\title{
Procedural Complications Following Diagnostic Coronary Angiography Are Related to the Operator's Experience and the Catheter Size
}

\author{
Peter Ammann, ${ }^{1 *}$ MD, Hans P. Brunner-La Rocca, ${ }^{2}$ MD, Walter Angehrn, ${ }^{1}$ MD, Hans Roelli, ${ }^{1}$ MD, \\ Markus Sagmeister, ${ }^{3}$ MD, and Hans Rickli ${ }^{1}$ MD
}

\begin{abstract}
Cardiac catheterization is performed routinely in hospitals all around the world. Extensive analysis of complications has been performed in the 1980s and early 1990s. However, because of the new therapeutic innovations based on advanced catheter technologies, these data may not apply to the present situation. Still, there are few data about procedural complications of diagnostic cardiac catheterization over the last 10 years. A total of 7,412 consecutive diagnostic cardiac catheterizations were performed between January 1990 and December 2000 and prospectively assessed in a registry. There were a total of 63 complications, of which $\mathbf{4 0}$ were minor and 23 major. Thus, the overall complication rate was $0.8 \%$, with a mortality rate of $0 \%$. Univariate analysis showed lower overall complication rate of senior physicians $(>500$ coronary angiographies performed; OR $=$ 0.58; 95\% Cl $=0.34-0.98 ; P=0.04)$, smaller catheter size $(<6,6,>6$ Fr: OR $=2.6$; $95 \%$ $\mathrm{Cl}=1.53-4.41 ; P=0.0004)$, and a higher rate in patients having left and right heart catheterization $(\mathrm{OR}=2.62 ; 95 \% \mathrm{Cl}=1.46-4.7 ; P=0.003)$. Major complications were associated with larger catheters $(<6,6,>6 \mathrm{Fr}$ : $\mathrm{OR}=2.35 ; 95 \% \mathrm{Cl}=1.0-5.51 ; P=0.05)$, whereas vascular complications occurred more often with higher body weight (per $10 \mathrm{~kg}$ : $\mathrm{OR}=1.4 ; 95 \% \mathrm{Cl}=1.01-1.95 ; P=0.04)$. Overall complication rate in diagnostic coronary angiography is very low and related to the experience of the performing cardiologist and catheter size. The only predicting risk factors for major complications in coronary angiography were catheter size and body weight. Cathet Cardiovasc Intervent 2003;59: 13-18. 2003 Wiley-Liss, Inc.
\end{abstract}

Key words: coronary angiography; complications; catheter size; stroke; experience

\section{INTRODUCTION}

In 1929, Werner Forssmann [1] was the first to advance a catheter into the heart. Nowadays, cardiac catheterization is performed routinely in hospitals all around the world. Extensive analyses of complications have been performed in the 1980s and early 1990 s, showing a relatively stable mortality rate between $0.1 \%$ and $0.2 \%$ and an overall complication rate between $0.8 \%$ and $1.8 \%$ [2-5]. However, there are few data about procedural complications of diagnostic cardiac catheterization over the last 10 years [6]. Complication rate may be significantly lower in recent years because advanced catheter technologies have improved cardiac catheterization significantly. The aim of the present study was therefore to investigate the complication rate in diagnostic angiography over the last years and to find potential risk factors for major and minor complications.

\section{MATERIALS AND METHODS}

Between January 1990 and December 2000, all periprocedural complications within $24 \mathrm{hr}$ of catheteriza- tion were assessed from a prospectively conducted, computer-assisted registry of all diagnostic coronary angiographies performed in a tertiary-referral center. The registry was started for reasons of quality control and for follow-up investigations of patients with coronary artery disease.

In all patients, a percutaneous femoral approach with insertion of a catheter sheath using a soft J-guidewire was

\footnotetext{
${ }^{1}$ Division of Cardiology, Department of Internal Medicine, Kantonsspital St. Gallen, St. Gallen, Switzerland

${ }^{2}$ Division of Cardiology, University Hospital, Basel, Switzerland ${ }^{3}$ Department of Internal Medicine, Kantonsspital St. Gallen, St. Gallen, Switzerland
}

*Correspondence to: Dr. Peter Ammann, Division of Cardiology, Kantonsspital St. Gallen, 9000 St. Gallen, Switzerland.

E-mail: peter.ammann@kssg.ch

Received 5 August 2002; Revision accepted 11 December 2002

DOI $10.1002 / \mathrm{ccd} .10489$

Published online in Wiley InterScience (www.interscience.wiley.com). 
performed after adequate local anesthesia with $10-20 \mathrm{ml}$ lidocaine $1 \%$. Only in cases of left and right heart catheterization was 2,500-5,000 IE heparin administered. In most of the cases, coronary angiography and ventriculography were performed using right and left Judkins and pigtail catheters. Swan-Ganz catheters and Cournand catheters were used for right heart catheterization. Changes of heart catheters always were performed after inserting the soft J-guidewire into the thoracic aorta. After finishing cardiac catheterization, an initial manual compression of the arterial puncture site was performed for at least $5 \mathrm{~min}$ following a compressive bandage at the site of the arterial approach for $6 \mathrm{hr}$ with the use of $6 \mathrm{Fr}$ or larger size and $4 \mathrm{hr}$ with the use of $5 \mathrm{Fr}$ or smaller size. Major complications were defined as stroke, perforation of cardiac chamber, dissection or occlusion of coronary artery, dissection or hematoma of peripheral vessel needing intervention. All other complications were defined as minor complications. To analyze the impact of the technical experience, physicians who performed the angiographies were divided in those in training and senior cardiologists (i.e., > 500 angiographies performed). Three senior cardiologists and six cardiologists in training performed all angiographies; $78 \%$ of all procedures were performed by senior cardiologists and $22 \%$ by physicians in training.

\section{Statistics}

Categorical data are presented as numbers (percentage) and continuous data as mean \pm standard deviation or median value (range) as appropriate. Fisher's exact test was used to compare categorical variables and MannWhitney U-test statistic was used to compare continuous variables. Univariate logistic regression analysis was used to calculate odds ratio (OR) for the development of complications. Independence of statistically significant risk factors in univariate analysis was tested in multivariate logistic regression analysis.

Because of the small number of major and vascular complications, no multivariate analysis was performed for these endpoints. A two-tailed $P$ value $\leq 0.05$ was considered statistically significant. Analyses were performed using the statistical package SPSS for Windows 9.0.

\section{RESULTS}

Between January 1990 and December 2000, 7,528 diagnostic coronary angiographies were performed in our catheter laboratory. In 116 (1.5\%), data were not complete and these cases were excluded from further analysis. Thus, a total of 7,412 diagnostic coronary angiographies in a total of 6,468 patients (age, $59.4 \pm 10.7$ years)
TABLE I. Characteristics of Study Population and Interventions

\begin{tabular}{lc}
\hline Characteristic & $\begin{array}{c}\text { All patients } \\
(\mathrm{n}=7,412)\end{array}$ \\
\hline Age, years & $59 \pm 11$ \\
$\begin{array}{l}\text { Body mass index, }{ }^{\mathrm{a}} \mathrm{kg} / \mathrm{m}^{2} \\
\text { History of smoking }\end{array}$ & $25 \pm 5$ \\
$\begin{array}{l}\text { Hypercholesterolemia (total cholesterol } \\
\quad>200 \mathrm{mg} / \mathrm{dl} \text { ) }\end{array}$ & $5755(78)$ \\
$\begin{array}{l}\text { Arterial Hypertension (blood pressure }>140 / \\
\quad 90 \mathrm{~mm} \mathrm{Hg})\end{array}$ & $3641(49)$ \\
$\begin{array}{l}\text { Diabetes }(\mathrm{patients} \text { needing insulin or oral } \\
\quad \text { antidiabetics) }\end{array}$ & $782(11)$ \\
$\begin{array}{l}\text { Heart failure during catheterization (Killip } \\
\quad \text { class }>1)\end{array}$ & $743(10)$ \\
$\begin{array}{l}\text { History of myocardial infarction } \\
\text { Catheterizations performed by experienced } \\
\text { physicians }(>500 \text { angiographies) }\end{array}$ & $3,414(46)$ \\
Left heart catheterization & $5,706(76)$ \\
Combined left/right heart catheterization & $6,634(89.5)$ \\
\hline
\end{tabular}

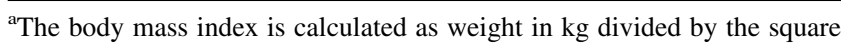
of the height in $\mathrm{m}$; it is indicated as mean $\pm \mathrm{SD}$.

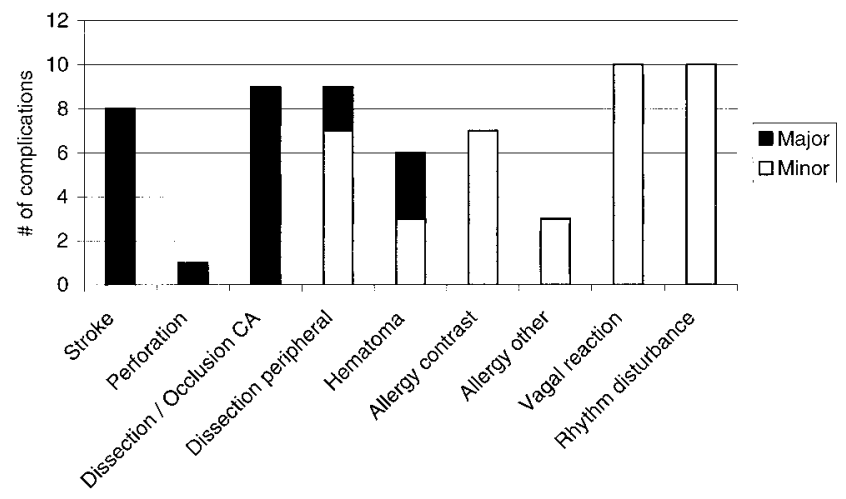

Fig. 1. Absolute numbers of the different major and minor procedural complications related to diagnostic coronary angiography between 1990 and 2000.

were included in the analysis. Characteristics of these procedures are depicted in Table I.

In $63(0.8 \%)$ of the 7,412 diagnostic coronary angiographies analyzed, periprocedural complications were observed (Fig. 1). Major complications occurred in 23 $(0.3 \%)$ instances, whereas the other $40(0.5 \%)$ complications were minor. Although there was an annual increase in the number of cardiac catheterizations performed between 1990 and 2000, the complication rate remained relatively stable, showing a decrease in the complication rate over the years, although this trend was not statistically significant (Fig. 2).

A number of risk factors for the rate of complications could be identified (Table II). The most important was the size of the catheter used. During the study period, smaller catheter sizes became available from initially 7 


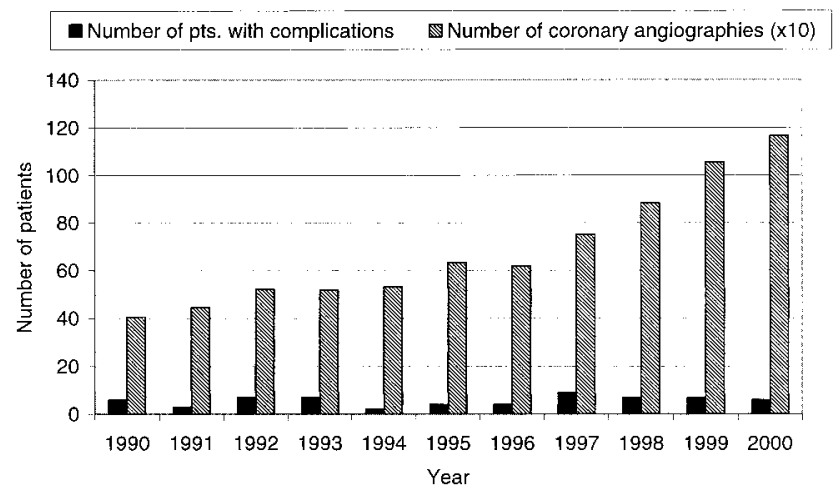

Fig. 2. Absolute numbers of patients with procedural complications related to diagnostic coronary angiography in respect to the absolute number of coronary angiographies between 1990 and 2000.

and $8 \mathrm{Fr}$ catheters in the early 1990s to 5 and $4 \mathrm{Fr}$ catheters in the late 1990s (Fig. 3). Smaller catheter size was associated with a lower complication rate $(1.9 \%>6$ Fr vs. $0.8 \% 6 \mathrm{Fr}$ vs. $0.2 \%<6 \mathrm{Fr} ; \mathrm{OR}=2.6 ; 95 \% \mathrm{CI}=$ $1.53-4.41 ; P=0.0004)$. In addition, complications occurred more often if combined left and right catheterization was performed $(1.9 \%$ vs. $0.7 \%$; OR $=2.62 ; 95 \%$ $\mathrm{CI}=1.46-4.7 ; P=0.003)$. Also, the experience of the physician was significantly related to the complication rate $(0.7 \%$ vs. $1.3 \%$; $\mathrm{OR}=0.58 ; 95 \% \mathrm{CI}=0.34-0.98$; $P=0.04)$. Finally, complications were more common in heart failure patients $(1.7 \%$ vs. $0.8 \%$; OR $=2.16 ; 95 \%$ $\mathrm{CI}=1.12-4.16 ; P=0.03)$. In multivariate analysis, the size of the catheters $(\mathrm{OR}=2.44$ per category $[<6 \mathrm{Fr}$ vs. $6 \mathrm{Fr}$ vs. $>6 \mathrm{Fr}] ; 95 \% \mathrm{CI}=1.56-3.82 ; P=0.001)$, combined left and right catheterization $(\mathrm{OR}=2.1 ; 95 \%$ $\mathrm{CI}=1.15-3.82 ; P=0.02)$, and the experience of the physician $(\mathrm{OR}=0.54 ; 95 \% \mathrm{CI}=0.32-0.91 ; P=0.02)$ were independently related to the complication rate.

Major complications were associated with smoking $(0.5$ vs. $0.2 \% ; \mathrm{OR}=2.76 ; 95 \% \mathrm{CI}=1.14-6.73 ; P=$ $0.02)$ and larger catheters $(0.6 \%>6 \mathrm{Fr}$ vs. $0.3 \% 6 \mathrm{Fr}$ vs. $0.0 \%<6$ Fr: $\mathrm{OR}=2.35 ; 95 \% \mathrm{CI}=1.00-5.51 ; P=$ $0.05)$. They also tended to be related to body weight (79.8 \pm 11.6 vs. $76.2 \pm 12.8 \mathrm{~kg} ; P=0.07)$. Vascular complications were significantly associated with smoking $(0.4 \%$ vs. $0.1 \%$; $\mathrm{OR}=3.93 ; 95 \% \mathrm{CI}=1.28-12.06$; $P=0.01)$ and higher body weight $(82.3 \pm 9.4$ vs. $76.2 \pm$ $12.8 \mathrm{~kg} ; P=0.02$ ), whereas the trend for catheter size did not reach statistical significance $(0.5 \%>6 \mathrm{Fr}$ vs. $0.2 \% 6$ Fr vs. $0.0 \%<6$ Fr: $\mathrm{OR}=2.54 ; 95 \% \mathrm{CI}=$ $0.93-7.02 ; P=0.07)$.

\section{DISCUSSION}

The most important finding of the present investigation was a $0 \%$ mortality in diagnostic cardiac catheter-

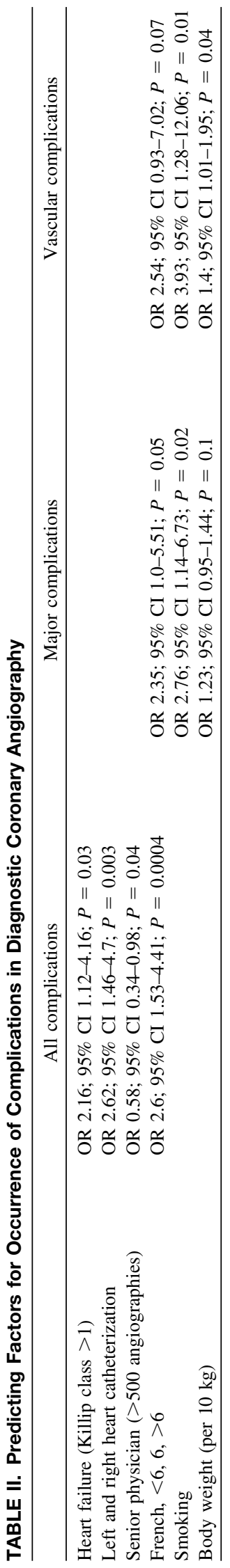




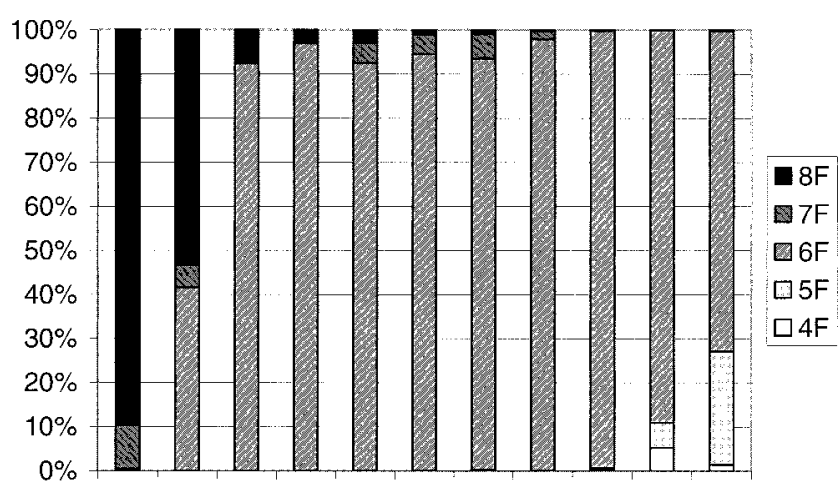

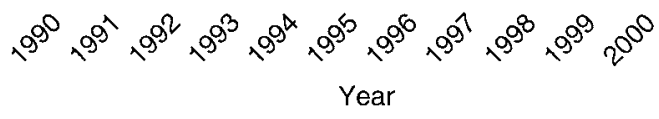

Fig. 3. Use of different sizes of catheters in French ( $1 \mathrm{Fr}=0.33$ $\mathrm{mm}$ ) between 1990 and 2000.

ization in the catheter laboratory and within $24 \mathrm{hr}$ of hospitalization over the last decade in contrary to previous studies reporting the results of large registries [2-5].

Also, the overall complication rate was low and tended to decrease over the last years. This decrease was related to an increasing use of small catheters. Furthermore, lack of experience and concomitant right heart catheterization were identified as independent risk factors for the occurrence of complications.

It is important to discuss if a selection bias toward referring only low-risk patients to coronary angiography could have led to these favorable results. Between 1990 and April 1998, diagnostic procedures were performed in our catheter laboratory only. If PTCA was needed, patients were referred to a partner hospital. Due to our location in the northeastern part of Switzerland as the only hospital performing coronary angiographies within 80 miles, it is nearly impossible that high-risk patients were excluded from analysis. However, we cannot completely exclude the possibility that in some cases highrisk patients were primarily transferred by helicopter to a center performing PTCA, but this was not the common practice in our country during the study period. Therefore, the percentage of high-risk patients sent to other hospitals performing PTCA seems to be neglectable. Between April 1998 and December 2000, 325 percutaneous transluminal coronary angioplasties were performed following diagnostic angiography. Complication rate was very low because only low-risk interventions were performed. In 6 of the reported 62 complications, PTCA was performed following diagnostic angiography. In two cases, there was an allergy to the contrast agent, in one case PTCA was performed due to dissection of the LAD during diagnostic angiography, two patients developed pseudoaneurysm of the femoral artery, and one patient suffered from stroke. Therefore, PTCA could only be responsible for three of the complications reported.

Most of the studies investigating the complication rate of diagnostic cardiac catheterization have been performed more than a decade ago. Since the Collaborative Studies in Coronary Artery Surgery Registry data in 1979, the analysis from the Society for Cardiac Angiography and Interventions registry from 1984 to 1987 and data from the British Cardiac Society from 1990 to 1991 were reported. Mortality in these registries ranged from $0.1 \%$ to $0.2 \%$ and complication rates from $0.8 \%$ to $1.8 \%$ [2-5]. The fast development toward more sophisticated and advanced catheter technologies in the last decade may have, however, an important impact on the complication rate. This hypothesis is supported by our results in that both the mortality and the complication rate are below those reported previously. Our data are in line with $0 \%$ mortality in outpatient cardiac catheterization reported from other investigators [7-9]. However, these studies included a smaller number of procedures in a highly selected low-risk population for procedural complications and may therefore underestimate mortality rate in real-world practice.

Apart from the comparison of the complication rate with historical data, the main aim of this study was to identify potential risk factors for the overall as well as major and vascular complications. Our data show that the size of the catheter was the most important risk factor not only for the overall complication rate but also for the occurrence of major and, though not statistically significant, vascular complications. Diagnostic catheter size has been progressively decreased over the last years in order to reduce complications. Our results, however, are in certain contrast with recent studies, which could not demonstrate a reduced complication rate with the use of small 4, 5, or 6 Fr catheters [10,11]. However, these studies were statistically underpowered to demonstrate differences in mortality or complication rates since only small numbers of patients (100 and 405 patients, respectively) were included.

Lack of experience of the physician was another important risk factors for complications. If an experienced physician performed the study, the complication rate was nearly halved. In coronary angioplasty, it has been shown that laboratory volumes of $>200$ angioplasty cases per year and 75 cases per operator are necessary to minimize complications [12]. In coronary angiography corresponding data are lacking, although the skill and experience of the operator and the laboratory staff have been postulated as important factors for reducing complication rate [13]. This assumption is supported by our report. In our prospectively conducted registry, the complication rate was strongly associated with the number of angiographies 
performed in the past ( $>500$ vs. $<500$ angiographies performed).

Finally, the combined left and right heart catheterization was associated with a higher complication rate. This was, however, primarily caused by vagal reactions and rhythm disturbances (data not shown), whereas the other complications, particularly local and vascular, were not more common. These data are in certain contrast to the pooled data from de Bono [4], which showed no difference in complication and mortality rates in respect to combined left and right heart catheterizations as compared to left heart catheterization alone.

\section{Major and Vascular Complications}

Despite the favorable decrease of complication rate related to advanced catheter technologies and the experience of the physicians, stroke and dissection/occlusion of peripheral or coronary arteries still remain a major problem in cardiac catheterization. In our series, stroke occurred in $0.11 \%$, with a persistent neurological defect in only three patients $(0.04 \%)$ and dissection of peripheral or coronary arteries in $0.2 \%$. Our data are comparable with a $0.1 \%$ stroke rate reported by Sagal et al. [14] in a series of 7,266 diagnostic angiographies and a $0 \%-$ $0.34 \%$ rate of vascular complications and dissection of coronary arteries reported from the Joint Audit Committee of the British Cardiac Society and Royal College of Physicians [4]. Attempts toward better management of stroke patients such as systemic or intra-arterial thrombolysis to improve outcome have been very encouraging $[15,16]$. Whether this may also help in patients suffering from stroke following catheterization remains to be investigated. In case of peripheral vascular disease, a brachial or radial approach may reduce major vascular complication rate [17].

Also with respect to major and vascular complications, we found the catheter size of importance. Furthermore, they were more common in smokers. This was mainly caused by an increased rate in stroke and peripheral dissection. Although not proven by this study, it may be speculated that advanced atherosclerosis of the aorta and the iliacal arteries as seen in smokers $[18,19]$ is related to this increased risk. Another risk factor, particularly of vascular complications, was a high body weight. This may not come as a surprise since increased body weight is associated with numerous cardiovascular risk factors [20] and puncture as well as closure of the access site may be more difficult in obese patients.

Others did not find the same risk factor for major and vascular complications as we did. Thus, major complications in coronary angiography occurred more often in moribund patients, cardiogenic shock (which was not investigated in our study), acute myocardial infarction, valvular heart disease, renal insufficiency, and conges- tive heart failure [21]. However, the overall low rate of major complications, particularly in our study, makes it difficult to define accurately the most important risk factors for major complications. Moreover, there were important differences in the patient population, making a direct comparison difficult.

\section{Study Limitations}

Despite the prospective nature of the registry, analyses of data were retrospective. Furthermore, data were incomplete in $116(1.5 \%)$ patients. These patients were excluded from further analysis. It may be argued that including these patients could have significantly influenced our results. However, the proportion of the excluded patients was small and their characteristics did not differ from the population included in the study. It is noteworthy that the complication rate was low, which might reduce the statistical power of the study. However, the main goal of the present study was to show the low complication rate and a $0 \%$ mortality within $24 \mathrm{hr}$ of diagnostic coronary angiography during the last decade in a real-world setting. Finally, due to the design of the present study, some potential contributing factors for worse outcome in coronary angiography such as reduced creatinine clearance were not analyzed.

The development and introduction of smaller catheter sizes in coronary angiography over the last 10 years are significantly associated with reduced complication rate in coronary angiography. Mortality rate has become extremely low. The operator's experience $(>500$ angiographies performed), a negative history of smoking, and normal body weight were independent predictors for good outcome after coronary angiography.

\section{REFERENCES}

1. Forssmann W. Die Sondierung des rechten Herzens. Klin Wochenschr 1929;8:2085.

2. Davis K, Kennedy JW, Kemp HG Jr, Judkins MP, Gosselin AJ, Killip T. Complications of coronary angiography from the Collaborative Study of Coronary Artery Surgery (CASS). Circulation 1979;59:1105-1112.

3. Johnson LW, Lozner EC, Johnson S, Krone R, Pichard AD, Vetrovec GW, Noto TJ. Coronary angiography 1984-1987: a report of the Registry of the Society for Cardiac Angiography and Intervention, I, results and complications. Cathet Cardiovasc Diagn 1989;17:5-10.

4. de Bono D. Complications of diagnostic cardiac catheterization: results from 34,041 patients in the United Kingdom confidential enquiry into cardiac catheter complications-the Joint Audit Committee of the British Cardiac Society and Royal College of Physicians of London. Br Heart J 1993;70:297-300.

5. Noto TJ Jr, Johnson LW, Krone R, Weaver WF, Clark DA, Kramer JR Jr, Vetrovec GW. Cardiac catheterization 1990: a report of the Registry of the Society for Cardiac Angiography and Interventions (SCA\&I). Cathet Cardiovasc Diagn 1991;24:75-83. 
6. Chandrasekar B, Doucet S, Bilodeau L, Crepeau J, deGuise P, Gregoire J, Gallo R, Cote G, Bonan R, Joyal M, Gosselin G, Tanguay JF, Dyrda I, Bois M, Pasternac A. Complications of cardiac catheterization in the current era: a single-center experience. Cathet Cardiovasc Intervent 2001;52:289-295.

7. Clements SD Jr, Gatlin S. Outpatient cardiac catheterization: a report of 3000 cases. Clin Cardiol 1991;14:477-480.

8. Bersin RM, Elliott CM, Elliott AV, Fedor JM, Gallagher JJ, Jordan L, Simonton CA $3^{\text {rd }}$, Svenson RH, Wilson BH, Zimmern SH. Mobile cardiac catheterization registry: report of the first 1001 patients. Cathet Cardiovasc Diagn 1994;31:1-7.

9. Fierens E. Outpatient coronary angiography. Cathet Cardiovasc Diagn 1984;10:27-32.

10. Lefevre T, Morice MC, Bonan R, Dumas P, Louvard Y, Karrillon G, Loubeyre C, Piechaud JF. Coronary angiography using 4 or 6 French diagnostic catheters: a prospective, randomized study. J Invas Cardiol 2001;13:674-677.

11. Metz D, Chapoutot L, Brasselet C, Jolly D. Randomized evaluation of four versus five French catheters for transfemoral coronary angiography. Clin Cardiol 1999;22:29-32.

12. Kimmel SE, Berlin JA, Laskey WK. The relationship between coronary angioplasty procedure volume and major complications. JAMA 1995;274:1137-1142.

13. ACC/AHA Guidelines for Coronary Angiography. A report of the American College of Cardiology/American Heart Association Task Force on Practice Guidelines (Committee on Coronary Angiography). J Am Coll Cardiol 1999;33:1756-1824.

14. Segal AZ, Abernethy WB, Palacios IF, BeLue R, Rordorf G.
Stroke as a complication of cardiac catheterization: risk factors and clinical features. Neurology 2001;56:975-977.

15. Hacke W, Kaste M, Fieschi C, Toni D, Lesaffre E, von Kummer R, Boysen G, Bluhmki E, Hoxter G, Mahagne MH, et al. Intravenous thrombolysis with recombinant tissue plasminogen activator for acute hemisperic stroke: the European Cooperative Acute Stroke Study (ECASS). JAMA 1995;274:1017-1025.

16. Keris V, Rudnicka S, Vorona V, Enina G, Tilgale B, Fricbergs $\mathrm{J}$. Combined intraarterial/intravenous thrombolysis for acute ischemic stroke. Am J Neuroradiol 2001;22:352-358.

17. Hildick-Smith DJ, Walsh JT, Lowe MD, Stone DL Schofield PM, Shapiro LM, Petch MC. Coronary angiography in the presence of peripheral vascular disease: femoral or brachial/radial approach? Cathet Cardiovasc Intervent 2000;49:32-37.

18. Tegos TJ, Kalodiki E, Sabetai MM, Nicolaides AN. The genesis of atherosclerosis and risk factors: a review. Angiology 2001;52: 89-98.

19. Howard G, Wagenknecht LE, Burke GL, Diez-Roux A, Evans GW, McGovern P, Nieto FJ, Tell GS. Cigarette smoking and progression of atherosclerosis: the Atherosclerosis Risk in Communities (ARIC) study. JAMA 1998;279:119-124.

20. Melanson KJ, McInnis KJ, Rippe JM, Blackburn G, Wilson PF. Obesity and cardiovascular disease risk: research update. Cardiol Rev 2001;9:202-207.

21. Laskey W, Boyle J, Johnson LW. Multvariable model for prediction of risk of significant complication during diagnostic cardiac catheterization: the Registry Committee of the Society for Cardiac Angiography and Interventions. Cathet Cardiovasc Diagn 1993; 30:185-190. 